IV Congreso Internacional Estética y Política Poéticas del desacuerdo para una democracia plural 16 y 17 de octubre. Valencia

Doi: http://dx.doi.org/10.4995/CEP4.2019.10515

\title{
El problema de la soberanía y la tentación rojiparda
}

\section{Jaime Paulino Cuenca}

Jaime.paulino.cuenca@gmail.com

\begin{abstract}
Resumen
En este texto ensayamos un diagnóstico y algunas respuestas a los interrogantes abiertos en el campo teórico progresista tras la el retorno de la soberanía como concepto central para pensar el horizonte político. A lo largo del texto repasamos las tradiciones globalista y soberanista del campo teórico de la izquierda y las contrastamos con el enfoque soberanista de la nueva revolución conservadora
\end{abstract}

Palabras clave: Soberanía, Pueblo, Populismo, Negri, Laclau, Marx, Kojève, Duguin

\begin{abstract}
In this paper we test a diagnosis and some answers to questions opened in the progressive theoretical field, after the return of sovereignty as a central concept to think the political horizon. Throughout the text, we review the globalist and sovereignty traditions of the left theoretical field and contrast them with the sovereignty approach of the new conservative revolution.
\end{abstract}

Keywords:, Sovereignty, People, Populism, Negri, Laclau, Marx, Kojève, Duguin 


\section{La tradición "globalista" de la izquierda}

La tradición marxista ha venido prescribiendo la filiación de las identidades políticas emancipadoras dentro lo que podríamos llamar un "globalismo puro". El rechazo a la "comunidad nacional" como sujeto de cambio, o al menos a su inscripción estatal, ha sido frecuente dentro del pensamiento revolucionario que ha leído, casi sistemáticamente, las aspiraciones nacionalistas como un retroceso histórico. La clase como sujeto político se entiende y se expresa en el conflicto interno a las relaciones productivas que, dentro del despliegue capitalista, tienen alcance claramente global, y no en el conflicto entre naciones.

No habría que olvidar que, para Marx, la burguesía no era una clase pasiva presa de la historia, sino una clase esencialmente revolucionaria capaz de las mayores hazañas, entre ellas la de disolver toda mística detrás de las relaciones sociales y de conectar el mundo con los anclajes materiales de la producción y el consumo como en ningún momento previo de la historia. La "simplificación de los antagonismos de clase" (Marx y Engels, 2011), que anuncia el Manifiesto Comunista como principal característica del mundo burgués, desplaza cualquier otro tipo de conflicto político. De tal manera, la actualización del proletariado como clase revolucionaria debería darse a la misma escala a la que operaba el capitalismo y su clase dominante para forzar su contradicción interna. La dimensión nacional del proletariado configuraría una identidad secundaria con una potencia revolucionaria limitada y un efecto, en el mejor de los casos, coyuntural para el progreso histórico. En el peor, sería el instrumento para velar la dimensión histórica del conflicto y, en consecuencia, una potencia reaccionaria. De ahí la censura que, tradicionalmente, despertó el nacionalismo en los círculos teóricos y militantes de la izquierda política.

Sólo durante el despliegue de los movimientos políticos vinculados a la descolonización, dentro de la pugna geopolítica entre primer y segundo mundo tras la Segunda Guerra Mundial, y con el paulatino descrédito de la centralidad europea en el imaginario revolucionario (y la promesa de un "hombre nuevo"), pudo surgir en el siglo XX una idea de "pueblo" con rasgos nacionales y atributos genuinamente emancipadores. Frantz Fanon, a principios de los 60, sería clave en consolidar esa imagen que nutrió teóricamente numerosos movimientos de "liberación nacional" y que, con matices, armonizó tradición marxista y aspiración nacional. Sin salirse mucho de la intuición general de las tesis leninistas, su análisis de la arquitectura de los imperios coloniales posibilitaría una traducción efectiva de conflicto de clase a conflicto nacional en el enfrentamiento entre nativos proletarios y colonizadores burgueses (Fanon, 2010).

Esta línea de pensamiento se mantuvo como referente dentro de un marxismo cada vez menos hegemónico durante los 80 y los 90 hasta que se popularizaron bases teóricas nuevas que facilitaron, en cierta forma, el retorno a posiciones globalistas puras. La tesis de Imperio (Negri y Hardt, 2005), gestada durante el auge neoliberal tras casi una década tras el derrumbe del segundo mundo, reorienta la prospectiva de la acción política emancipadora por fuera de la codificación antimperialista. Radicalizando y actualizando a Marx, Negri lee los nuevos escenarios de conflicto político dentro de la reordenación semiótica, afectiva, cognitiva y, sin duda, tecnológica de las nuevas formas de producción de valor. Y, yendo más allá de la hipótesis posmodernista, presenta un Imperio sin centro físico, reticular en vez de piramidal, financiero en vez de industrial y que desborda la contradicción entre colonia y metrópolis. En consecuencia, el nuevo escenario de conflicto social, desenvuelto al margen de los rigores geopolíticos previos, estaría sentando las condiciones de una potencia emancipadora propia sobre la que los relatos identitarios fuertes tendrían una influencia muy limitada. Las condiciones teóricas de este enfoque, en el que se dan encuentro la tradición postestructuralista, la recepción spinoziana de Marx del seminario de Althusser y fecundos estudios de sociología del trabajo de la Escuela de la Regulación, son demasiado amplias para abordarlas con el mínimo detalle exigible. A efectos de lo que proponemos, baste decir que la Multitud, como se refiere Negri a esta nueva subjetividad que contrapone por igual a "Pueblo" y "Clase", constituye una suma de singularidades esencialmente creativas y productivas, irreductibles a una única identidad nacional o de clase y cuyo espacio de actuación es irrepresentable tanto por una organización de vanguardia como por un Estado. Este enfoque teórico está detrás del ciclo de movilizaciones que han agitado los primeros años del siglo XXI. Y como efecto derivado ha supuesto la impugnación teórica más directa a la imagen soberana del poder y su forma de expresión política. 


\section{El colapso del orden neoliberal y la demanda de seguridad}

Una impugnación de la imagen soberana del poder que se mueve en paralelo a la imagen de un mundo postsoberanista que ya habría estado avanzando el neoliberalismo desde, cuanto menos, la década de los 80 . De hecho, si tuviésemos que esbozar el proyecto neoliberal en dos trazos gruesos, bien podrían ser los siguientes:

1) Frente a la escuela liberal clásica que entiende que el mercado es la forma natural de relación social entre individuos libres, el neoliberalismo sostendría que, aunque el mercado es la mejor forma de organización social, no es natural. Su tarea consistiría en emplear las instituciones estatales para generar mercado de y formas de relación competitiva y mercantil de manera artificial en espacios de la vida social en los que estas no existirían por si mismas.

2) Una consecuencia directa habría sido debilitar la soberanía del Estado-Nación en favor de las instituciones supraestatales, tanto de carácter político (Unión Europea) como de carácter regulador (instituciones de Breton Woods), a fin de sustituir una arquitectura mundial de soberanías enfrentadas por una gobernanza global que multiplicase la influencia de los actores económicos (como representantes genuinos de la sociedad civil) frente a los actores políticos.

Así, el comienzo del siglo XXI habría dejado un panorama en el que, tanto los movimientos teóricos de izquierda, como el desarrollo exitoso de la institucionalidad neoliberal dejaban poco margen al retorno al modelo de soberanía como horizonte político. Sin embargo, esta situación ha dado un giro evidente en los últimos años y la soberanía vuelve a ser el eje, por izquierda y derecha, desde el que orientar y practicar la política. Entender cómo se ha producido este cambio implica entender cómo la Gran Recesión, lejos de ser un accidente más dentro de los ciclos de la economía capitalista global, ha supuesto una crisis del orden neoliberal del mundo con todas sus consecuencias. Y eso implica, ante todo, que el neoliberalismo ha dejado de ser un orden.

Desde el advenimiento de lo que Fukuyama (1992), tras 1989, popularizó como "fin de la historia" el neoliberalismo se había mantenido no sólo como una estructura institucional que armonizaba el modelo de estado-nación con el despliegue de la globalización económica. También comprendía una dinámica cultural que estimulaba el deseo y alimentaba el imaginario de participación en ese mundo. Y como se ha sugerido previamente, la clave del orden neoliberal no se encontraría tanto en las políticas que desplazaban el ordenamiento soberano hacia el desarrollo de la gobernanza global (antes bien, estas serían sus consecuencias), como en esa capacidad para estimular imaginarios. Y en esto es fundamental el papel que la posmodernidad, la condición cultural y libidinal más potente del siglo XX, ha podido jugar dentro del paradigma neoliberal. Una posmodernidad que, caracterizada por Lyotard a principios de los 80, representaría el fin de los "grandes relatos" en tanto que la estructura productiva habría transmutado, finalmente, todo el espacio cultural y cognitivo en espacio mercantilizable y dejado al sujeto sin privacidad con respecto a la lógica mercantil. Huelga decir que el éxito de esta forma de redefinir las relaciones sociales y el paradigma de producción y consumo (con el necesario estímulo de un capital financiero desbocado) fue indiscutible hasta que se quebró, por la vía de los hechos, su capacidad para mantener un horizonte deseable.

Así, cuando hablamos de crisis del orden neoliberal no nos referimos al derrumbe de sus instituciones, sino a su incapacidad como paradigma, de satisfacer las expectativas de la población. Y más particularmente: a su incapacidad para satisfacer la demanda de estabilidad y seguridad que la crisis habría vuelto irremediablemente actual. Esa falta de alma (o muerte anímica) de la institucionalidad neoliberal desvela la realidad personal como precariedad y desamparo absoluto, no sólo como accidente sino con claras consecuencias existenciales. La normalización de la precariedad que agudiza la Gran Recesión deja de ser la historia de una derrota personal circunstancial en un modelo competitivo para empezar a ser el principio desde el cual cualquier individuo se ve obligado a contemplar su futuro.

De hecho, puede decirse que hoy el neoliberalismo es un sistema tan hegemónico institucionalmente como decadente en lo intelectual. Pasada la Gran Recesión, el modelo neoliberal se encuentra en estado de inercia, carente de motivación e incapaz de articular ideas o pensamiento nuevo. Y, por perder, ha perdido hasta lo más referencial: un modelo geopolítico imperial. Hoy, el mundo neoliberal se aproxima cada vez más a ser el deshecho de un mundo ya pasado, omnipresente 
pero incapaz de seducir a nadie. El sonado fracaso de Europa y el agravamiento de la crisis de EEUU como actor político y económico global, dibujan un escenario sin referencias que, sin embargo, no encuentra un contramodelo alternativo y sigue constituyendo la totalidad de lo existente.

La necesidad de la comunidad, y la búsqueda del pueblo como categoría central de esa necesidad, nace de ese vacío. Y, en cierta medida, virando hacia la soberanía y los lindes del Estado-Nación, ha hecho descabalgar la potencia práctica del discurso globalista de izquierda.

\section{Sobre pueblo y soberanía}

Es razonable decir que el retorno de la soberanía es, en buena medida, un movimiento de refugio frente al desorden que lega el neoliberalismo. Pero debe señalarse que ese retorno no es tanto la celebración acrítica del Estado sino el redespliegue del imaginario del pueblo. La reivindicación de lo popular supone el renovado acceso, jugando con Kant, a una idea regulativa de la política que establezca referencias claras de seguridad y justicia.

No se trata, por tanto, de que la soberanía disponga de un valor político en sí mismo, sino de que, desde ella, se encarne una idea de comunidad que ordene la crisis existencial que lega la crisis económica. La soberanía cumpliría, por así decirlo, la función de materializar alguna idea de pueblo. De hecho, en las tradiciones políticas democratista y contractualista, el concepto pueblo es anímico, elusivo y carece de referencias materiales y objetivas desde las que poder abordarse.

Puede observarse, en contraste, cómo la sociología y la teoría política sí nos ofrece un concepto propio como instancia objetiva y cuantificable: la población. Este término, cuyo origen moderno está vinculado al nacimiento de las ciencias de la vida entre los siglos XVIII y XIX, refleja una medición estadística de valores vitales (Foucault, 2008). La población es síntesis y sumatorio de un conjunto de características de individuos (longevidad, morbilidad, salubridad) útiles al desarrollo del poder Estatal y la economía capitalista de la Revolución Industrial. Hay una ciencia sobre la población como correlato y extensión necesaria de una ciencia del Estado. Pero, de la misma forma, no es posible una ciencia sobre el pueblo, cuya presencia discursiva, invocada generalmente en primera persona del plural, siempre ha supuesto la toma de partido en la legitimación o la censura del poder dentro del Estado.

En el mismo sentido en el que no hay una ciencia sobre el pueblo, su consideración filosófica lo contempla a la escala del acontecimiento histórico y de la representación trascendente. Como una figura divina que sanciona el resultado de una contienda política. El pueblo se manifiesta como el cuerpo místico de un Estado, y por la misma razón, como una estructura esencial de orden. El pueblo aparece siempre como respuesta emergente en una disputa por la legitimidad del poder. Hobbes ilustraba radicalmente esta condición en De Cive (Hobbes, 2000) cuando decía, hablando de los riesgos de disolución interna del Estado, que en una monarquía los súbditos en rebeldía son una multitud (es decir, un colectivo disgregado sin voz unificada ni autorizada) mientras que el rey sería, por paradójico que pudiera parecer, el pueblo que se les opone. Y, en una imagen inversa de la misma estructura, habría que considerar a las revoluciones exitosas que alumbraron repúblicas nuevas en la modernidad y situaron al pueblo como expresión política genuina frente a los excesos de la tiranía. Así, el We The People, con el que da comienzo el texto constitucional de los Estados Unidos, constituye la voz de legitimidad de un poder nuevo que sustituye el orden viejo.

Bien sea para preservar el statu quo bien para fundar un orden nuevo, esta posición ambivalente y regulativa del pueblo como promesa de orden justo y autoridad es ilustrativa de su recuperación contemporánea.

\section{Una nueva, y gramsciana, revolución conservadora}

Pero ¿desde dónde se invoca hoy al pueblo? Esta pregunta, seguramente, sea fundamental para considerar el debate contemporáneo en torno a la soberanía y su potencialidad política. La respuesta, aunque toma como referencia ineludible lo dicho más arriba, señala dos espacios netamente diferentes. De un lado, la tradición de pensamiento populista inaugurada por Laclau. Pero, de otro, creo que puede empezar a hablarse de una nueva, y gramsciana, revolución conservadora (a la imagen de la de la segunda década del siglo XX), vinculada directamente a la Nueva Derecha francesa, 
entre cuyas referencias pueden contarse a viejos conocidos del pensamiento reaccionario como Alexandr Duguin o Alain de Benoist y cuya implantación política es cada vez mayor en los Estados europeos.

Sobre el populismo de Laclau se ha dicho suficiente durante los últimos años como para aspirar a añadir algo nuevo en este breve espacio. Basta, para esta comunicación, recordar que se integra en lo que Olivier Marchart ha bautizado como pensamiento político posfundacional, esto es, la reubicación de la teoría política después de la deconstrucción heideggeriana de sus fundamentos tradicionales. La política no se instituiría desde el descubrimiento de sus presuntos fundamentos (por ejemplo, la condición genética o cultural de una población determinada o la determinación económica de una estructura social) sino desde la dinámica de sus relaciones. Y entre ellas, la más básica y schmittiana: la relación amigo-enemigo. El pueblo estudiado por la tesis populista está siempre ausente, existe como promesa de reconciliación imposible, pero sobre todo funciona como operador negativo, como mecanismo de señalamiento y exclusión de su adversario, el no-pueblo. Esta condición hace que su realidad esté ligada a una función enunciativa hasta el punto de que, en consonancia con las consecuencias posmetafísicas del giro lingüístico, la propia ontología de la política quede redimensionada dentro del ámbito discursivo.

Para los teóricos de la nueva revolución conservadora, como puede intuirse, las sutilezas metafísicas del discurso populista son materia más bien exótica. Su posicionamiento lo abre, de una manera mucho más tradicional, un debate clásico en la filosofía política del siglo XX entre Kojève y Leo Strauss sobre la inevitabilidad o reversibilidad de la historia (Kojève y Strauss, 2013). Kojève, un marxista de derechas que hizo una interpretación sistemática del determinismo histórico en Hegel y terminó siendo la gran influencia de Fukuyama, había llegado a sostener en los 60 que la sociedad de consumo de los Estados Unidos y el american way of life constituía lo más próximo a la realización del sueño marxista de una sociedad sin clases. Al tiempo, anunciaba la tendencia irrefrenable hacia un Estado Mundial que habría de universalizar el régimen de derechos nacidos de la revolución francesa y clausurar la historia, dando lugar a una nueva, y felicitante, animalidad humana en la que cualquier deseo material encontrase vías de satisfacción. En esa dirección, la universalización abiertamente anticomunitaria de la sociedad de consumo supondría un paso decisivo. Enfrente, Leo Strauss, compartiendo buena parte del diagnóstico, sostenía la necesidad de lo contrario: hacer girar a la inversa el reloj de la historia para recuperar valores comunitarios que, en una línea de interpretación conservadora del pensamiento nietzscheano, permitiesen evitar la atrofia anímica y la condición nihilista a la que estaría condenada la humanidad.

En la órbita de esa valoración straussiana, el retorno a la soberanía nacional y al espíritu comunitario que se propone desde las filas de la nueva revolución conservadora puede ordenarse en torno a tres ideas:

1) La ubicación de una derecha política radicalmente enfrentada a la derecha neoliberal.

2) La afirmación cultural de Europa como espacio espiritual contrapuesto a la modernidad, al individualismo occidental y a la sociedad de consumo (contraposición Europa-Occidente).

3) La abjuración de un orden globalista y atlantista (tesis geopolítica) que suponga la victoria cultural del liberalismo tal y como describe el escenario de Kojève.

La forma en la que se presentan las últimas dos ideas hacen aparecer del suplemento novedoso que este grupo añade a lo que, de otro modo, se habría quedado en una recuperación vulgar de clásicos del pensamiento conservador y reaccionario: integrar como propios elementos diagnósticos centrales de la crítica cultural marxista y, más específicamente, del pensamiento gramsciano.

De hecho, según plantea Duguin, dentro de este colectivo se gesta una figura intelectual novedosa: el "gramsciano de derechas". Esto implica una doble caracterización, analítica y propositiva: de un lado, el reconocimiento de la autonomía relativa del plano de acción de la sociedad civil a la hora de construir hegemonía cultural. Y, de otro, posicionarse abiertamente en contra de esa hegemonía. A diferencia del uso mediado que podría hacer la crítica marxista tradicional de Gramsci, el conflicto en torno a la hegemonía liberal no se daría de manera relativa a alguna concepción de necesidad histórica o de algún grado de determinación económica, sino de pura confrontación política en sentido schmittiano (en este punto no muy lejos de Laclau). Traducido a posiciones políticas, no habría que ofrecer una respuesta al liberalismo dentro del "después" de su ordenamiento del mundo, como si fuese parte de una secuencia histórica, sino rearmarse espiritualmente contra el régimen existente. 
Bien es cierto que la capacidad de seducción de este tipo de posición estaría limitado a la posibilidad, más bien remota, de compartir previamente el núcleo fundamental del pensamiento reaccionario: esto es, la convicción de que existe una fuente de valor moral genuina en la tradición europea premoderna y que el liberalismo y el capitalismo (y el desencantamiento del mundo que arrastran consigo) constituyen la nulificación de la grandeza de la cultura europea. Pero en el contexto de crisis efectiva del orden neoliberal y la demanda, casi existencial, de una estructura comunitaria que restituya la seguridad perdida tras la crisis, las circunstancias pueden serle bastante más favorables.

\section{Oportunidades para una soberanía de derechas}

Las oportunidades y ventajas políticas materiales para un discurso soberanista de la nueva revolución conservadora bien podrían caracterizarse, aunque de manera trivial, de la siguiente manera:

1) Presenta un discurso conservador articulado mediante buena parte del núcleo teórico de la izquierda política, dibujando un escenario casi paralelo a cómo el discurso neoliberal habría colonizado a la izquierda socialdemócrata durante los 80 y 90 . Esto ofrece la ventaja de presentar una impugnación general al sistema institucional vigente y ofrecer un horizonte popular con una estela outsider que interpelase por igual a sensibilidades de izquierda y derecha.

2) Aprovecha la incapacidad histórica de la izquierda política para construir un imaginario de orden para aparecer como única alternativa y fuente de certezas, ofreciendo un relato fuerte y accesible desde los valores morales conservadores aún presentes en buena parte de la sociedad (aquello viejo que no termina de morir) para situar en el mapa su propia idea de pueblo y de legitimidad del poder.

3) Aprovecha, igualmente, el desmantelamiento del Estado ejecutado por la institucionalidad neoliberal para hacer girar el discurso del orden en un terreno familiar: dentro de la gestión, típicamente conservadora, de las acciones represivas y punitivas. Si el neoliberalismo había reducido la capacidad de expresión del Estado a la gestión de fronteras y la seguridad interna, no es extraño que la reivindicación de la soberanía como elemento constitutivo de seguridad y la identificación de lo popular en momentos de incertidumbre pueda desplegase antes como una seguridad contra otro que como seguridad frente a las carencias materiales.

4) Pero hay una cuarta propuesta, a la vez más sutil e intelectualmente relevante, que caracteriza y refuerza su propuesta: denunciar la herencia del $68 \mathrm{y}$, en términos generales, a buena parte de la teoría surgida al calor de la Nueva Izquierda como revolución pasiva que habría dado lugar al orden neoliberal. Cuando Fusaro, a quien podríamos incluir sin demasiada dificultad dentro de esta revolución conservadora, reclama un movimiento político con "ideas de izquierda y valores de derecha" lo hace contra lo que él denuncia, con indiscutible ánimo provocador, como una "izquierda fucsia" aliada del capitalismo. Es decir, una izquierda que asume la diversidad, disgrega la comunidad, se opone a los valores tradicionales y renuncia a una identidad fuerte, nacional o de clase, reconociendo y favoreciendo la pluralidad de sujetos políticos.

Es en este último punto en el que el uso de Gramsci por parte de los conservadores es más inteligente: ofrece un diagnóstico de continuidad entre contracultura y neoliberalismo que no exige participar de sus presupuestos morales y que dispone de una capacidad seductora suficiente como para atraer, con cierta naturalidad, a un considerable número de sensibilidades vinculadas a la vieja izquierda. Complementariamente, abunda en una intuición que ya fue secretamente común para cierta izquierda: que la modernidad, y su núcleo liberal, se entienden mucho mejor desde sus límites externos, incluso desde la mirada de sus adversarios (que casi siempre son reaccionarios), que desde sus propios términos internos. Así, las ideas de Duguin y de Benoist, como anteriormente las de Maistre, Donoso Cortés o Schmitt, posiblemente contribuyan más a componer una imagen de nuestro tiempo que las de la enésima iteración de autores del contractualismo anglosajón. Tales podrían ser las coordenadas de la tentación rojiparda que el pensamiento conservador hace desfilar ante la izquierda. 


\section{A modo de conclusión: dificultades y alternativas}

La nueva revolución conservadora ha aprendido a leer a Gramsci y a Marx y a experimentar política de trinchera con ellos sin demasiados prejuicios. De hecho, los pilares de la tradición intelectual de la izquierda les ofrece instrumentos válidos para una batalla que libran con creciente éxito y de manera cotidiana. Para la izquierda, en cambio, muchos de estos instrumentos siguen teniendo un valor más ritual que práctico: celebrados en la intimidad de la tradición, pero desarticulados en el despliegue de propuestas políticas. Limitando, en consecuencia, su influencia en tiempos de crisis de paradigma. Hasta tal punto es así que podría dudarse si al fin de la historia neoliberal no le estaría sucediendo el retorno a una peculiar historia reaccionaria destinada a corregir la crisis cultural del 68 y la crisis geopolítica del 89.

Pero situándonos en el lado terrenal de las profecías y la necesidad histórica, entendemos que la izquierda dispone, todavía, de un campo de acción suficiente en tanto sea capaz de reconocer e integrar como propia la siguiente premisa: que el deseo de comunidad y su articulación política, el populismo, no es una opción dentro de la política contemporánea que puedan ser aceptada o rechazada, sino la condición de toda política contemporánea. En consecuencia, que la extensión del momento populista al auge actual de la extrema derecha a manos de la revolución conservadora, lejos de constituir su clausura, confirma la hipótesis abierta al comienzo de la crisis del neoliberalismo.

Este reconocimiento plantea, al menos, dos grandes retos (y, ciertamente, ninguna garantía de resolverlos a tiempo). El primero es interno a la sacralidad de las tradiciones de izquierda: deben dejar de ser izquierda, ocasionalmente, populista para empezar a ser populismo de izquierda. Y, paradójicamente, el efecto de este cambio de modelo no debería suponer la exclusión de las hipótesis no populistas, sino, al contrario, la inclusión en su interior todos los enfoques y tradiciones de la manera más laica y, seguramente, autocontradictoria que pudiera sostenerse. Lejos de la lucha escolástica y doctrinal de la izquierda, habría que ensayar un programa teórico que integrase tanto las virtudes diagnósticas del enfoque posoperaista de Negri como las ventajas prácticas del modelo populista de Laclau.

El segundo es institucional y geopolítico, y es que, a fuerza de pensar casi exclusivamente en términos de la resistencia al capitalismo o a la globalización, la tradición teórica de izquierdas sigue careciendo de una propuesta unívoca y contundente de organización de relaciones internacionales y, consecuentemente, de un modelo de Estado integrado en ellas. Mientras la casilla geopolítica y Estatal sigan difusas, cuando no vacías, en el mapa conceptual de la izquierda, toda su capacidad teórica se pondrá antes al servicio de sus adversarios intelectuales que de su propuesta política. Lo urgente no es tanto denunciar el pensamiento reaccionario como contribuir a construir una ejemplaridad alternativa que, ante todo, ofrezca un horizonte de seguridad propio.

La vulnerabilidad heredada sólo se rectifica desde la seguridad del colectivo. El reto es definir qué colectividad se promociona y qué régimen de exclusiones le dan sentido. Porque de la escisión desde que se decida operar, se dispondrá de un populismo transformador y positivo o se tendrá enfrente un populismo tenebroso y triste.

\section{Referencias}

FANON, F. (2010) Los condenados de la tierra. Madrid: FCE

FoucAult, M. (2008) Seguridad, territorio y población. Madrid: Akal

FukuYama, F. (1992) El fin de la historia y el último hombre. Barcelona: Planeta

Hobbes, T. (2000) De Cive. Madrid: Alianza

KojèVe, A. Y STRauss, L. (2013) On Tyranny. Chicago: University of Chicago Press

LACLAU, E. (2005) La razón populista. Buenos Aires: FCE

LYOTARD, F. (2006) La condición postmoderna. Madrid: Cátedra

MARChart, O. (2009) El pensamiento político posfundacional. Buenos Aires: FCE

MARX, K Y ENGELS, F. (2011) Manifiesto comunista. Madrid: Alianza

Negri, A. y HaRdT, M. (2005) Imperio. Barcelona: Paidós 